\title{
Robot-assisted adrenalectomy: current perspectives
}

This article was published in the following Dove Press journal:

Robotic Surgery: Research and Reviews

5 January 2017

Number of times this article has been viewed

\author{
Mrinal Pahwa \\ Department of Urology and Renal \\ Transplant, GRIPMER, Sir Ganga Ram \\ Hospital, New Delhi, India
}

\begin{abstract}
Laparoscopy has established itself as the procedure of choice for performing adrenalectomy in benign adrenal disorders. Although laparoscopy scores heavily over open approach in terms of lesser blood loss, pain, shorter hospital stay and better cosmesis, it is riddled with certain shortcomings such as the need of dexterity, two-dimensional vision, dependence on an assistant for camera, etc. Robotic surgery promises to overcome these limitations. Multiple series have established that robotic adrenalectomy is a safe and effective procedure as conventional laparoscopy. Recently, robotic surgery has been found to be precise and accurate in performing partial adrenalectomy in hereditary adrenal syndrome cases. Other advances like single-port surgery have expanded the horizon and indications of robotic surgery. This review aims at studying the current evidence available for the effectiveness of robot-assisted adrenalectomy and defining its current status in managing adrenal disorders.
\end{abstract}

Keywords: robotics, adrenal gland, adrenalectomy, laparoscopy, pheochromocytoma

\section{Introduction}

Laparoscopic adrenalectomy (LA) has been recognized as the procedure of choice for the management of, especially benign, adrenal disorders. Various studies have proved the feasibility, efficacy and safety of this approach. ${ }^{1-4}$ As compared to open adrenalectomy (OA), LA involves lesser blood loss, lesser pain and shorter hospital stay and offers better cosmesis. ${ }^{5-12}$ Despite all these advantages, LA has been restricted to a handful of experienced surgeons at high-volume centers because of certain technical drawbacks like two-dimensional view, stiff non-articulating instruments, dependence on an assistant for camera, etc. Robot-assisted adrenalectomy (RA) is the recent addition to the armamentarium of surgeons. RA overcomes the limitations of laparoscopic surgery by providing a three-dimensional magnified view, better ergonomics, control of the camera and multi-articulated instruments using Endowrist technology to the surgeons. Recent studies, reviews and meta-analyses have tried to establish its superiority over LA and OA in terms of faster convalescence and lesser complication rate. ${ }^{13-25}$ Higher cost and longer operating times have although prevented RA from gaining widespread acceptance. A recent large international series has shown that conventional laparoscopy and laparoendoscopic single-site surgery seem to be the most common adopted techniques, whereas minilaparoscopy and RA seem to be gaining popularity at a slower rate. ${ }^{26}$ In this review, the current status of robotic approach in performing adrenalectomy has been analyzed.
Correspondence: Mrinal Pahwa Department of Urology, Sir Ganga Ram Hospital, Room No. 1240, 2nd Floor, Old Rajinder Nagar, New Delhi I I0060, India Tel +9| 98| I558 8287

Email mrinal.pahwa@sgrh.com
Robotic Surgery: Research and Reviews 2017:4 I-6

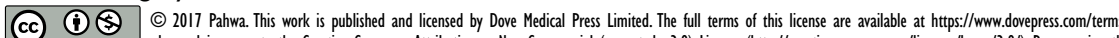

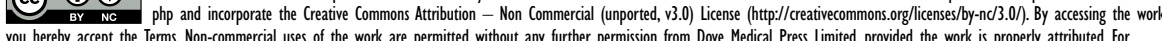
you herbby accept the Terms. Non-commercial uses of the work are permitted without any further permission from Dove Medical Press Limited, provided the work is properly attributed. For permission for commercial use of this work, please see paragraphs 4.2 and 5 of our Terms (https:/www.dovepress.com/terms.php). 


\section{Feasibility}

In 2000, Horgan and Vanuno first reported the use of robot in performing laparoscopic bilateral adrenalectomy. ${ }^{27}$ Since then, many authors published their experience of performing robot-assisted LA in small series of patients until Winter et al published the first series on 30 patients in 2006 . Three different surgeons at a single center performed the surgeries. The median operative (OR) time was 185 minutes, postoperative complication rate was $7 \%$ and median hospital stay was 2 days and there was no conversion to open or laparoscopic surgery. ${ }^{28}$ Since then, more than 50 studies have been published describing RA, but few studies have included more than 20 cases. This is the minimum number of cases required for achieving the learning curve of RA. ${ }^{16}$

Table 1 describes the various case series that have evaluated the feasibility of robotic adrenalectomy ( $>20$ patients). Subsequent series have shown comparatively decreasing OR time with decreasing conversion rate. Multiple studies in recent past comparing robotic adrenalectomy with LA have shown nil conversion rate.

\section{RA vs LA}

Multiple series have compared laparoscopic and robotic transperitoneal adrenalectomy. Most of these studies have been retrospective observational comparative studies, ${ }^{13,14,16-24,26}$ and

Table I Robotic adrenalectomy feasibility series

\begin{tabular}{|c|c|c|c|c|}
\hline Study & $\begin{array}{l}\text { No. of } \\
\text { patients }\end{array}$ & $\begin{array}{l}\text { OR time } \\
\text { (minutes) }\end{array}$ & $\begin{array}{l}\text { Conversion } \\
\text { rate }(\%)\end{array}$ & $\begin{array}{l}\text { Morbidity } \\
\text { (\%) }\end{array}$ \\
\hline Brunaud et $\mathrm{al}^{29}$ & 100 & 95 & 5 & 8 \\
\hline Giulianotti et $\mathrm{al}^{30}$ & $4 I$ & 118 & 0 & 4.8 \\
\hline Nordenström et $\mathrm{al}^{|3|}$ & 100 & 113 & 7 & 13 \\
\hline Raman et $\mathrm{al}^{32}$ & 40 & 117 & 4 & 10 \\
\hline Pahwa et $\mathrm{al}^{33}$ & 25 & $139 \pm 30$ & 0 & 12 \\
\hline
\end{tabular}

Abbreviation: OR, operative. only one of them was a randomized controlled trial. ${ }^{15}$ One of the first series comparing LA with robotic adrenalectomy was by Morino et al who evaluated outcomes in 10 patients who underwent laparoscopic and robotic adrenalectomy. ${ }^{15}$ The authors observed that although the laparoscopic approach took less time (115 vs 169 minutes), it had a higher conversion rate (4 vs 0 ) and longer length of stay (LOS; 5.7 vs 5.4 days) as compared to robotic approach. Brunaud et al performed a retrospective analysis of a large series of 50 robotic and 59 laparoscopic adrenalectomies. They found that though the OR time was longer in the robotic group (189 vs 159 minutes), it was associated with a lesser blood loss (49 vs $71 \mathrm{~mL}$ ) and shorter LOS (6.3 vs 6.9 days) with similar conversion rate (4 vs 4 ). ${ }^{16}$ Table 2 describes various studies that have compared the outcomes in laparoscopic and robotic groups.

Brandao et al recently conducted a systematic review and meta-analysis comparing laparoscopic and robotic adrenalectomy. ${ }^{20}$ This meta-analysis of nine studies, eight retrospective observational and one randomized controlled trial, included 600 patients (277 RA vs 323 LA). Although they did not observe any difference in terms of conversion rates, OR time, or postoperative complications, the robotic group was found to have less blood loss and a short hospital stay. As a part of the International Consultation on Urologic Diseases and European Association of Urology consultation on Minimally Invasive Surgery in Urology, an extensive methodological systemic review of the literature of laparoscopic and robotic adrenalectomy in the treatment of adrenal diseases was performed. The literature was searched systematically till January 2014 to identify studies comparing the safety and efficacy of different modalities of minimally invasive adrenal surgery techniques. The authors presented major findings in an evidence-based fashion and

Table 2 Studies comparing LA and RA

\begin{tabular}{|c|c|c|c|c|c|}
\hline Study & $\begin{array}{l}\text { No. of patients } \\
\text { (RA vs LA) }\end{array}$ & $\begin{array}{l}\text { OR time (minutes) } \\
\text { (RA vs LA) }\end{array}$ & $\begin{array}{l}\text { EBL (mL) } \\
\text { (RA vs LA) }\end{array}$ & $\begin{array}{l}\text { Conversion } \\
\text { (RA vs LA) }\end{array}$ & $\begin{array}{l}\text { Complications } \\
\text { (RA vs LA) }\end{array}$ \\
\hline Morino et $\mathrm{al}^{15}$ & 10 vs 10 & 169 vs 114 & NR & 4 vs 0 & 0 vs 0 \\
\hline Brunaud et al $^{16}$ & 50 vs 59 & 189 vs 159 & 49 vs 71 & 4 vs 4 & 5 vs 9 \\
\hline Agcaoglu et $\mathrm{al}^{14}$ & 24 vs 38 & 159 vs 187 & 84 vs 167 & I vs 4 & 0 vs 0 \\
\hline Agcaoglu et al ${ }^{17}$ & 31 vs 31 & 163 vs 166 & 25 vs 36 & NR & 0 vs 0 \\
\hline Karabulut et $\mathrm{al}^{13}$ & 50 vs 50 & 166 vs 164 & $4 I$ vs 4 I & I vs 2 & I vs 5 \\
\hline Pineda-Solis et $\mathrm{al}^{21}$ & 30 vs 30 & 190 vs 160 & 30 vs 55 & 0 vs 5 & 0 vs 0 \\
\hline Aksoy et $\mathrm{al}^{18}$ & 42 vs 57 & 186 vs 187 & 50 vs 77 & 0 vs 3 & I vs 2 \\
\hline You et $\mathrm{al}^{22}$ & 15 vs 8 & 207 vs 183 & NR & 0 vs 0 & 2 vs 2 \\
\hline Aliyev et al $^{19}$ & 25 vs 40 & I49 vs 178 & 36 vs 43 & I vs 3 & I vs 2 \\
\hline Brandao et $\mathrm{al}^{23}$ & 30 vs 46 & 120 vs 120 & 50 vs 100 & 0 vs 1 & 7 vs II \\
\hline Pavan et $\mathrm{al}^{26}$ & 80 vs 337 & 150 vs 120 & 50 vs 50 & 2 vs 10 & 22 vs 40 \\
\hline Lairmore et $\mathrm{al}^{24}$ & 66 vs 17 & I 52.8 vs 177.3 & I 03.4 vs 46.5 & 8 vs I & 15 vs 11.8 \\
\hline
\end{tabular}

Abbreviations: LA, laparoscopic adrenalectomy; RA, robot-assisted adrenalectomy; OR, operative; EBL, estimated blood loss; NR, not recorded. 
provided a set of recommendations. They concluded that RA might be considered an alternative to LA but requires further study (Grade B). ${ }^{34}$

Tang et al performed a meta-analysis that included eight studies (232 cases and 297 controls) assessing RA vs LA, where six were prospective and two were retrospective. Patients in the LA group had significantly shorter OR time (weighted mean difference [WMD] = 17.52 minutes; 95\% confidence interval [CI], 3.48-31.56; $p=0.01$ ), but patients in the RA group had significantly lesser estimated blood loss $(\mathrm{EBL}$; WMD $=-19.00 \mathrm{~mL} ; 95 \% \mathrm{CI},-34.58$ to -3.41 ; $p=0.02)$ and shorter $\operatorname{LOS}(\mathrm{WMD}=-0.35$ day; $95 \% \mathrm{CI},-0.51$ to $-0.19 ; p<0.001)$. Patients in both the groups had similar conversion rates and overall complications. ${ }^{35}$ The same findings have been corroborated in another meta-analysis and systematic review by Chai et al. ${ }^{36}$

RA has been compared with conventional LA in a certain subset of patients too. Aksoy et al compared outcomes of these two approaches in obese patients (42 patients in robotic group and 57 in laparoscopic group). The authors observed similar OR times (186.1 vs 187.3 minutes), less $\operatorname{EBL}$ (50.3 vs $76.6 \mathrm{~mL}$ ) and shorter LOS (1.2 vs 1.7 days) in the robotic group. There were no conversions in the robotic group, whereas the conversion rate was $5.2 \%$ in the laparoscopic group. ${ }^{18}$ Aliyev et al compared perioperative outcomes and efficacy of laparoscopic and robotic adrenalectomies in patients with pheochromocytoma. Patients in robotic group had a shorter OR time (149 vs 178 minutes), less EBL (36 vs $43 \mathrm{~mL}$ ), fewer conversions (1 vs 3) and shorter LOS (1.2 vs 1.7 days). ${ }^{19}$ Agcaoglu et al performed a prospective comparative study of 24 patients in robotic group with 38 patients in laparoscopic group undergoing adrenalectomy for large tumors (mean size: $6.5 \pm 0.4$ [robotic] vs $6.2 \pm 0.3 \mathrm{~cm}$ [laparoscopic]). The robotic group had a shorter OR (159.4 \pm 13.4 vs $187.2 \pm 8.3$ minutes, $p=0.043)$, shorter LOS (1.4 \pm 0.2 vs $1.9 \pm 0.1$ days, $p=0.009)$ and lesser conversion rate ( $4 \%$ vs $11 \%, p=0.43)$ but similar EBL ( $p=0.147)$. The perioperative morbidity was nil in the robotic group and $2.7 \%$ in the laparoscopic group. ${ }^{14}$

Studies comparing RA with OA are less. Probst et al recently published their trial comparing RA with OA. They analyzed 28 matched pairs of patients with respect to their characteristics, perioperative outcomes and cost effectiveness. Patients in RA group benefited from a shorter LOS $(11.1 \pm 4.8$ vs $6.8 \pm 1.2$ days, $p<0.01)$ and intermediate care treatment $(2.3 \pm 1.7$ vs $1.2 \pm 0.4$ days, $p<0.01)$. The mean operating time was longer for RA (128.5 \pm 46.5 vs $102.2 \pm$ 44.5 minutes, $p=0.03$ ), but the OR time of the last $10 \mathrm{RA}$ procedures (mean: $97.1 \pm 35.2$ minutes) was similar to that of OA. There was no difference in the rate of complications between the two groups. ${ }^{37}$

\section{Posterior retroperitoneoscopic adrenalectomy (PRA)}

Theoretically, posterior retroperitoneal approach of adrenalectomy offers distinct advantages like decreased chance of postoperative ileus and other intestinal complications, as peritoneum is not breached, along with decreased postoperative pain. Ludwig et al first reported on their experience of performing robotic PRA on six patients. The mean tumor size in the study population was $2.8 \mathrm{~cm}$ with a mean OR time of 121 minutes. The OR time was further reduced to a mean of 57 minutes for five patients where the entire dissection was performed robotically. The authors did not observe any morbidity or mortality. ${ }^{38}$ Berber et al published their experience of performing RA on 23 patients, of whom eight underwent retroperitoneal adrenalectomy. The average tumor size in this study was $2.9 \mathrm{~cm}$ with an average OR time of over 3.5 hours. More importantly, the docking time decreased to 15 minutes in the last four cases from 1 hour in the beginning of the study. According to the authors, patients with smaller tumors, bilateral disease and who have undergone multiple prior operations are best suited for retroperitoneal approach. ${ }^{39}$ The surgeons in both the series had a vast experience of performing retroperitoneoscopic surgery and robotic procedures.

Karabulut et al compared robotic adrenalectomy with the laparoscopic approach. Thirty-two patients were operated through transabdominal route and 18 were operated through posterior retroperitoneoscopic approach in both the laparoscopic and robotic groups. They did a step-by-step evaluation of OR time and found that both the LA and robotic PRA had similar OR times for each step except for shorter time for hemostasis in the robotic group $(23 \pm 4$ vs $42 \pm 9$ minutes, $p=0.03$ ). Later on, the same group published their results when they did a head-to-head comparison of laparoscopic and robotic PRA on 31 patients each. Although the mean (standard error of the mean, SEM) OR time was similar in both the groups, there was a significant difference in the mean (SEM) OR time of the last 21 cases of robotic-assisted PRA when compared to the laparoscopic group (139.1 [10.9] vs 167.7 [12.1] minutes, respectively; $p=0.046)$. The mean (SEM) EBL was similar in the robotic and laparoscopic groups (25.3 [10.2] and 35.6 [9.9] mL, respectively; $p=0.24$ ). The median hospital stay was 1 day for both groups. Both the groups had similar overall postoperative narcotic use. ${ }^{13}$ 
Lairmore et al performed a retrospective analysis of their minimally invasive adrenalectomy patients operated over the last 10 years by three different approaches. The study included 67 transperitoneal LA (TLA), 76 PRA and 17 robotassisted PRA (RAPRA) procedures. Tumor size in patients undergoing retroperitoneal adrenalectomy was smaller than in patients undergoing TLA ( 2.38 vs $3.6 \mathrm{~cm}, p<0.0001)$. Procedure time was significantly longer in the robotic group as compared to TLA/PRA (177 vs 153/133 minutes, $p=0.008$ ), but LOS significantly decreased ( 1.53 vs $2.82 / 1.85$ days, $p=0.004)$. Mean EBL was also lower for RAPRA than for LA $(46 \pm 25.4$ vs $103.4 \pm 153.8 \mathrm{~mL}, p=0.005) .{ }^{24}$

\section{RA for malignant diseases}

The use of minimally invasive approach for adrenocortical carcinoma is still a matter of debate. There has not been any prospective or randomized controlled trial comparing robotic or laparoscopy technique with open surgery. Some retrospective case reports and series have reported increased recurrence, peritoneal carcinomatosis, positive margins and local recurrence rates for laparoscopic cases compared to open surgery. ${ }^{40-44}$ Robotic adrenalectomy has so far been mainly performed for benign diseases, but it has also been reported for adrenal cancer, adrenal metastasis and oncocytoma. ${ }^{45-47}$

\section{Recent advances in robotic adrenalectomy}

\section{Single-port surgery}

Park et al first described the use of robot for performing single-port PRA. Five patients underwent the procedure. The mean tumor size, OR time and EBL were $1.48 \pm 0.28$ (range: $1.0-1.7) \mathrm{cm}, 159.4 \pm 57.6$ (range: $103-245$ ) minutes and 46.0 \pm 56.8 (range: $5-120) \mathrm{mL}$, respectively. The average time to oral intake and postoperative hospital stay was $0.65 \pm 0.11$ (range: $0.54-0.79$ ) days and $4.0 \pm 2.23$ (range: $3-8$ ) days, respectively. There were no conversions to open surgery or postoperative complications. ${ }^{48}$ Arghami et al described their experience of performing single-port RA in 16 patients and did a matched cohort analysis with 16 patients of LA. The OR time was $183 \pm 33$ minutes for single-port RA and 173 \pm 40 minutes for LA $(p=0.58)$. There was one conversion to OA (6\%) in each group, both because of bleeding on the right side during bilateral adrenalectomy. Two right-sided single-port RA patients required conversion to LA, one because of poor visualization. Both groups had similar pain scores (mean of 3.7 on a scale from 1 to 10 ) on postoperative day (POD) 1, and patients in the single-port RA used less narcotic pain medication in the first 24 hours after surgery (43 vs $84 \mathrm{mg}$ in LA group, $p=0.001$ ). The differences between the single-port RA group and LA group in LOS ( $2.3 \pm 0.5$ vs $3.1 \pm 0.9$ days, $p=0.23$ ), percentage of patients discharged on POD $1(56 \%$ vs $31 \%, p=0.10)$ and hospital cost ( $16 \%$ lower in single-port RA group, $p=0.17)$ did not reach statistical significance. ${ }^{49}$

Lee et al described their experience of performing robotic single-site adrenalectomy in 33 patients. The mean OR time was $118 \pm 25.8$ minutes. Sixty-seven percent of patients had pain scores of less than 4 (on a scale of 1-10). Seventy-four percent of patients were discharged on POD 1, and 96\% were discharged on POD 2. OR times were found to drop significantly from a mean of 124 to 103 minutes after 21 adrenalectomies $(p=0.05) .{ }^{50}$

\section{Robotic partial adrenalectomy}

Although total adrenalectomy has been traditionally advocated for bilateral adrenal disorders especially in hereditary syndromes like multiple endocrine neoplasia type 2, Von Hippel-Lindau disease and neurofibromatosis type I with decreased chances of recurrence, its benefits must be weighed against the morbidity of medical adrenal replacement therapy. Lifelong adrenal replacement therapy after bilateral adrenalectomy may predispose patients to osteoporosis, Addisonian crisis and decreased quality of life.$^{51}$ Hence, adrenal-sparing surgery or partial adrenalectomy has been suggested for patients with hereditary adrenal-producing syndromes, bilateral or multifocal lesions or solitary adrenal glands.

Kumar et al first described the technique of roboticassisted partial adrenalectomy in a patient with isolated adrenal metastasis. ${ }^{47}$ Boris et al described their initial experience of 13 partial adrenalectomies in 10 patients. Median OR time was 200 minutes, median blood loss was $150 \mathrm{~mL}$ and median tumor size was $2.7 \mathrm{~cm}$. No patient developed any intraoperative complication related to catecholamine surge like hypertensive crisis, prolonged hypotension, myocardial infarction or cerebrovascular accident. There were no recurrences, and only one patient required steroid replacement. ${ }^{52}$

There have been no comparative or prospective series of robotic and laparoscopic partial adrenalectomy. Hence, more research is required to fully define the role of robotic-assisted partial adrenalectomy.

\section{Cost}

Cost of robotic surgery is one of the prime and significant concerns for its widespread acceptance globally. The high 
cost associated with robot is mainly related to its high procurement cost, use of expensive surgical consumables and longer OR times along with high maintenance cost. Hence, a significant advantage needs to be established over other approaches so as to overcome this cost barrier. In general, cost of surgical consumables along with maintenance charges per procedure roughly adds $900-950 \$$ to the usual cost of the surgery. ${ }^{14}$ Another study estimated the additional cost to be around 1400-2900\$ for performing unilateral RA as compared to LA. ${ }^{53}$ A study by Bodner calculated that RA was approximately 1.5 times more costly than LA. ${ }^{54}$ On the contrary, Winter et al reported no significant difference between RA and OA or LA in terms of total cost. ${ }^{28}$ In another series, RA was found to be 2.3 times more expensive than LA. The authors suggested that this cost difference could be offset by multidisciplinary and high-volume use of robots by other surgical specialties and when depreciation of robotic equipment is distributed over 10 years instead of 5 years. ${ }^{29}$ Arghami et al showed that single-port RA was $16 \%$ less expensive than LA ( $84 \%$ $\pm 14 \%$ vs $100 \% \pm 16 \%$ ), although the difference was not statistically significant. ${ }^{49}$ Probst et al calculated that the additional cost of robotic procedure is $€ 2288$ per procedure provided there are more than 150 robotic procedures in a year. The expenses could be further reduced if there are more cases in high-volume centers. They also showed that the overall cost for patients undergoing RA was lower than that for patients undergoing OA because of difference in the length of hospital stay. ${ }^{37}$

\section{Conclusion}

Robotic approach is safe, feasible and as effective as conventional laparoscopy for performing adrenalectomy, especially for benign adrenal disorders. Depending upon the body habitus of the patient and experience of the surgeon, either transperitoneal route or retroperitoneal approach can be safely used to perform RA. Robotic surgery has also been demonstrated to be superior to laparoscopy in cases of large tumors, partial adrenalectomy and pheochromocytomas and in obese patients, but the number of patients has been limited in these retrospective series. Higher cost and lesser number of patients preclude the widespread adaption of this technique. High-volume centers and experienced surgeons can safely adapt this technology for better ergonomics of the surgeons and for better and precise dissection of adrenal tumors. Well-designed randomized controlled trials can clearly establish the exact status of robotics in performing radical adrenalectomy.

\section{Disclosure}

The author reports no conflicts of interest in this work.

\section{References}

1. Nehs MA, Ruan DT. Minimally invasive adrenal surgery: an update. Curr Opin Endocrinol Diabetes Obes. 2011;18(3):193-197.

2. Wang HS, Li CC, Chou YH, Wang CJ, Wu WJ, Huang CH. Comparison of laparoscopic adrenalectomy with open surgery for adrenal tumors. Kaohsiung J Med Sci. 2009;25(8):438-444.

3. Ariyan C, Strong VE. The current status of laparoscopic adrenalectomy Adv Surg. 2007;41:133-153.

4. Hall DW, Raman JD. Has laparoscopy impacted the indications for adrenalectomy? Curr Urol Rep. 2010;11(2):132-137.

5. Shen WT, Lim RC, Siperstein AE, et al. Laparoscopic vs open adrenalectomy for the treatment of primary hyperaldosteronism. Arch Surg. 1999;134(6):628-631; discussion 631-632.

6. Hallfeldt KK, Mussack T, Trupka A, Hohenbleicher F, Schmidbauer S. Laparoscopic lateral adrenalectomy versus open posterior adrenalectomy for the treatment of benign adrenal tumors. Surg Endosc. 2003;17(2):264-267.

7. Kim HH, Kim GH, Sung GT. Laparoscopic adrenalectomy for pheochromocytoma: comparison with conventional open adrenalectomy. J Endourol. 2004;18(3):251-255.

8. Ramachandran MS, Reid JA, Dolan SJ, Farling PA, Russell CF. Laparoscopic adrenalectomy versus open adrenalectomy: results from a retrospective comparative study. Ulster Med J. 2006;75(2):126-128.

9. Humphrey R, Gray D, Pautler S, Davies W. Laparoscopic compared with open adrenalectomy for resection of pheochromocytoma: a review of 47 cases. Can J Surg. 2008;51(4):276-280.

10. Kirshtein B, Yelle JD, Moloo H, Poulin E. Laparoscopic adrenalectomy for adrenal malignancy: a preliminary report comparing the short-term outcomes with open adrenalectomy. J Laparoendosc Adv Surg Tech A. 2008;18(1):42-46.

11. Lubikowski J, Uminski M, Andrysiak-Mamos E, et al. From open to laparoscopic adrenalectomy: thirty years' experience of one medical centre. Endokrynol Pol. 2010;61(1):94-101.

12. Mir MC, Klink JC, Guillotreau J, et al. Comparative outcomes of laparoscopic and open adrenalectomy for adrenocortical carcinoma: single, high-volume center experience. Ann Surg Oncol. 2013;20(5):1456-1461.

13. Karabulut K, Agcaoglu O, Aliyev S, Siperstein A, Berber E. Comparison of intraoperative time use and perioperative outcomes for robotic versus laparoscopic adrenalectomy. Surgery. 2012;151(4):537-542.

14. Agcaoglu O, Aliyev S, Karabulut K, Siperstein A, Berber E. Robotic vs laparoscopic posterior retroperitoneal adrenalectomy. Arch Surg. 2012;147(3):272-275.

15. Morino M, Beninca G, Giraudo G, Del Genio G, Rebecchi F, Garrone C. Robot-assisted vs laparoscopic adrenalectomy: a prospective randomized controlled trial. Surg Endosc. 2004;18(2):1742-1746.

16. Brunaud L, Bresler L, Ayav A, et al. Robotic-assisted adrenalectomy: what advantages compared to lateral transperitoneal laparoscopic adrenalectomy? Am J Surg. 2008;195(4):433-438.

17. Agcaoglu O, Aliyev S, Karabulut K, Mitchell J, Siperstein A, Berber E. Robotic versus laparoscopic resection of large adrenal tumors. Ann Surg Oncol. 2012;19(7):2288-2294.

18. Aksoy E, Taskin HE, Aliyev S, Mitchell J, Siperstein A, Berber E. Robotic versus laparoscopic adrenalectomy in obese patients. Surg Endosc. 2013;27(4):1233-1236.

19. Aliyev S, Karabulut K, Agcaoglu O, et al. Robotic versus laparoscopic adrenalectomy for pheochromocytoma. Ann Surg Oncol. 2013;20(13):4190-4194.

20. Brandao LF, Autorino R, Laydner H, et al. Robotic versus laparoscopic adrenalectomy: a systematic review and meta-analysis. Eur Urol. 2014;65(6):1154-1161.

21. Pineda-Solis K, Medina-Franco H, Heslin MJ. Robotic versus laparoscopic adrenalectomy: a comparative study in a high-volume center. Surg Endosc. 2013;27(2):599-602. 
22. You JY, Lee HY, Son GS, Lee JB, Bae JW, Kim HY. Comparison of robotic adrenalectomy with traditional laparoscopic adrenalectomy with a lateral transperitoneal approach: a single-surgeon experience. Int J Med Robot. 2013;9(3):345-350.

23. Brandao LF, Autorino R, Zargar H, et al. Robot-assisted laparoscopic adrenalectomy: step-by-step technique and comparative outcomes. Eur Urol. 2014;66(5):898-905.

24. Lairmore TC, Folek J, Govednik CM, Snyder SK. Improving minimally invasive adrenalectomy: selection of optimal approach and comparison of outcomes. World J Surg. 2016;40(7):1625-1631.

25. Pahwa M. Robot assisted adrenalectomy: a handy tool or glorified obsession? Gland Surg. 2015;4(4):279-282.

26. Pavan N, Autorino R, Lee H, et al. Impact of novel techniques on minimally invasive adrenal surgery: trends and outcomes from a contemporary international large series in urology. World J Urol. 2016; 34(10):1473-1479.

27. Horgan S, Vanuno D. Robots in laparoscopic surgery. J Laparoendosc Adv Surg Tech A. 2001;11(6):415-419.

28. Winter J, Talamini M, Stanfield C, et al. Thirty robotic adrenalectomies: a single institution's experience. Surg Endosc. 2006;20(1):119-124.

29. Brunaud L, Ayav A, Zarnegar R, et al. Prospective evaluation of 100 robotic-assisted unilateral adrenalectomies. Surgery. 2008;144(6): 995-1001.

30. Giulianotti P, Buchs N, Addeo P, et al. Robot-assisted adrenalectomy: a technical option for the surgeon? Int J Med Robot. 2011;7(1):27-32.

31. Nordenström E, Westerdahl J, Hallgrimsson P, Bergenfelz A. A prospective study of 100 robotically assisted laparoscopic adrenalectomies. J Robot Surg. 2011;5(2):127-131.

32. Raman SR, Shakov E, Carnevale N, et al. Robotic adrenalectomy by an open surgeon: are outcomes different? J Robot Surg. 2012;6(3):207-212.

33. Pahwa M, Pahwa AR, Batra R, et al. Robotic assisted laparoscopic adrenalectomy: initial experience from a tertiary care centre in India. J Minim Access Surg. 2015;11(1):83-86.

34. Ball MW, Hemal AK, Allaf ME. International Consultation on Urological Diseases and European Association of Urology International Consultation on Minimally Invasive Surgery in Urology: laparoscopic and robotic adrenalectomy. BJU Int. Epub 2016 Jul 19.

35. Tang K, Li H, Xia D, et al. Robot-assisted versus laparoscopic adrenalectomy: a systematic review and meta-analysis. J Laparoendosc $A d v$ Surg Tech A. 2015;25(3):187-195.

36. Chai YJ, Kwon H, Yu HW, et al. Systematic review of surgical approaches for adrenal tumors: lateral transperitoneal versus posterior retroperitoneal and laparoscopic versus robotic adrenalectomy. Int J Endocrinol. 2014;2014:918346.

37. Probst KA, Ohlmann CH, Saar M, Siemer S, Stoeckle M, Janssen M. Robotic-assisted vs open adrenalectomy: evaluation of cost effectiveness and perioperative outcome. BJU Int. Epub 2016 May 12.
38. Ludwig AT, Wagner KR, Lowry PS, et al. Robot-assisted posterior retroperitoneoscopic adrenalectomy. J Endourol. 2010;24(8): 1307-1314.

39. Berber E, Mitchell J, Milas M, et al. Robotic posterior retroperitoneal adrenalectomy. Arch Surg. 2010;145(8):781-784.

40. Gonzalez RJ, Shapiro S, Sarlis N, et al. Laparoscopic resection of adrenal cortical carcinoma: a cautionary note. Surgery. 2005;138(6): 1078-1086.

41. Leboulleux S, Deandreis D, Al Ghuzlan A, et al. Adrenocortical carcinoma: is the surgical approach a risk factor of peritoneal carcinomatosis? Eur J Endocrinol. 2010;162(6):1147-1153.

42. Lombardi CP, Raffaelli M, De Crea C, Bellantone R. Role of laparoscopy in the management of adrenal malignancies. J Surg Oncol. 2006; 94(2):128-131.

43. Miller BS, Gauger PG, Hammer GD, Doherty GM. Resection of adrenocortical carcinoma is less complete and local recurrence occurs sooner and more often after laparoscopic adrenalectomy than after open adrenalectomy. Surgery. 2012;152(6):1150-1157.

44. Porpiglia F, Fiori C, Daffara F, et al. Retrospective evaluation of the outcome of open versus laparoscopic adrenalectomy for stage I and II adrenocortical cancer. Eur Urol. 2010;57(5):873-878.

45. Zafar SS, Abaza R. Robot-assisted laparoscopic adrenalectomy for adrenocortical carcinoma: initial report and review of the literature. J Endourol. 2008;22(5):985-989.

46. Alguraan Z, Agcaoglu O, Aliyev S, Berber E. A rare case of merkel cell carcinoma metastasis to the adrenal resected robotically. Surg Laparosc Endosc Percutan Tech. 2013;23(1):e35-e37.

47. Kumar A, Hyams ES, Stifelman MD. Robot-assisted partial adrenalectomy for isolated adrenal metastasis. J Endourol. 2009;23(4): 651-654.

48. Park JH, Kim SY, Lee CR, et al. Robot-assisted posterior retroperitoneoscopic adrenalectomy using single-port access: technical feasibility and preliminary results. Ann Surg Oncol. 2013;20(8):2741-2745.

49. Arghami A, Dy BM, Bingener J, Osborn J, Richards ML. Single-port robotic-assisted adrenalectomy: feasibility, safety, and cost-effectiveness. JSLS. 2015;19(1):e2014.

50. Lee GS, Arghami A, Dy BM, McKenzie TJ, Thompson GB, Richards ML. Robotic single-site adrenalectomy. Surg Endosc. 2016;30(8): 3351-3356.

51. Oelkers W.Adrenal insufficiency. NEnglJMed. 1996;335(16):1206-1212.

52. Boris RS, Gupta G, Linehan WM, et al. Robot-assisted laparoscopic partial adrenalectomy: initial experience. Urology. 2011;77(4):775-780.

53. Barbash G, Glied SA. New technology and health care costs- the case of robot-assisted surgery. N Engl J Med. 2010;363(8):701-704.

54. Bodner J, Augustin F, Wykypiel H, et al. The da Vinci robotic system for general surgical applications: a critical interim appraisal. Swiss Med Wkly. 2005;135:674-678.
Robotic Surgery: Research and Reviews

\section{Publish your work in this journal}

Robotic Surgery: Research and Reviews is an international, peer reviewed, open access, online journal publishing original research, commentaries, reports, and reviews on the theory, use and application of robotics in surgical interventions. Articles on the use of supervisory-controlled robotic systems, telesurgical devices, and shared-control systems are

\section{Dovepress}

invited. The manuscript management system is completely online and includes a very quick and fair peer review system, which is all easy to use. Visit http://www.dovepress.com/testimonials.php to read real quotes from published authors. 